\title{
Sexually transmitted infections and PRO-LIVES: based on a clinical report*
}

\author{
Paulo Eduardo Neves Ferreira Velho ${ }^{1}$
}

DOI: http:/ /dx.doi.org/10.1590/abd1806-4841.20175433

\begin{abstract}
Physicians are also responsible for the increase in sexually transmitted infections. We report a case of patient inadequately monitored, that shows the importance of physicians to take basic measures with any individual at risk of acquiring such infections. We propose the following mnemonic acrostic: PRO-LIVES (Protection: usual and proper codom use, Responsibility, Other orientations, Laboratory tests - HIV infection, syphilis and B and C hepatitis-, Immunization: B hepatitis vaccination, Various: at least two patients, Ensure: case history and physical examination, Single dose treatment: whenever possible). Clinicians should take these measures when treating any patient who has been exposed to risk or with a diagnosis of sexually transmitted infections.
\end{abstract}

Keywords: Medical education; Medical errors; Sexually transmitted diseases; Teaching

The number of cases of sexually transmitted infections (STIs) is increasing. ${ }^{1}$ Postmodern cultural aspects - such as the refusal to follow rules, egocentrism, the transvaluation of values, and the devaluation of science at the expense of technology - may be involved in this growth. ${ }^{2}$

STIs, which are an important cause of morbidity and mortality, are usually underdiagnosed. They represent a high socio-economic cost both in developing and industrialized countries. ${ }^{3}$

Individuals affected by other STIs have a higher risk of contracting Human Immunodeficiency Virus (HIV). This interaction could explain $40 \%$ or more of HIV transmission cases. ${ }^{4}$

However, among other associated factors, poor medical IST training contributes to underdiagnoses, to inadequate treatment, and to the consequent spread of infectious diseases. Study conducted in Espirito Santo state, Brazil, showed that of the 1,803 cases of congenital syphilis reported in 2005, approximately $75 \%$ of pregnant women received prenatal care, but only $79 \%$ of these women were diagnosed during the period. $61 \%$ of partners were not referred for evaluation, and only $5 \%$ were treated properly. ${ }^{5}$ Another study showed that only 10 out of 83 physicians participating in the study were able to interpret syphilis serology properly. ${ }^{6}$

It is common that STI patients are not adequately investigated, oriented, or even treated. An example is the case report of a patient with condyloma affecting the balanopreputial region treated with cryotherapy by a dermatologist and not investigated for other STIs. Only after two years, the appearance of a new lesion caused by HPV led to the diagnosis of coinfection with HBV, HCV, and HIV. CD4 counts suggested past infection caused by HIV (Figure 1).
This case exemplifies poor medical STI training. Based on the experience gained in STI curriculum with a multidisciplinary team at the School of Medical Sciences at State University of Campinas, we propose the following acrostic to facilitate the memorization of basic behaviors involved in the care of any patient with a risk of exposure: PRO-LIVES.

Protection (Condoms): when used correctly during sexual relationships, condoms are effective in preventing STIs. In relation to HIV transmission, the proper use of condoms among serodiscordant couples is $70-80 \%$ effective. However, study revealed that

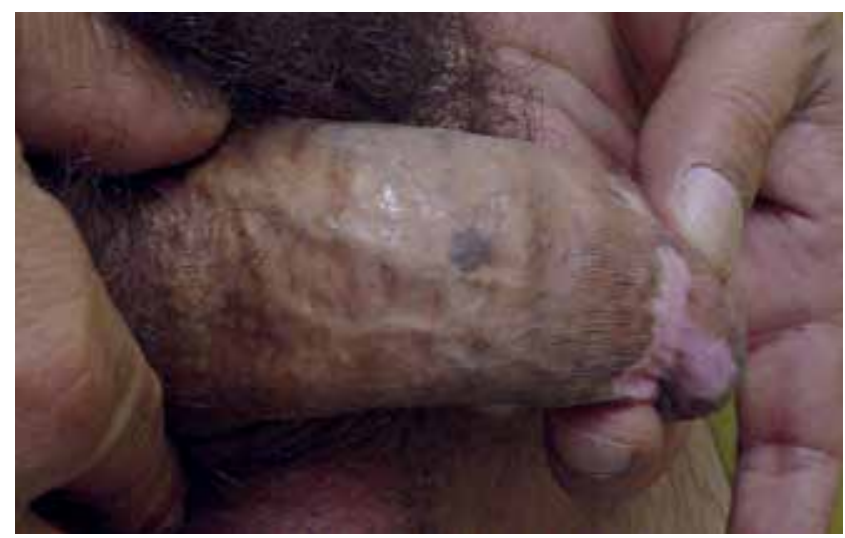

Figure 1: Patient with bowenoid papulosis in penile body and coinfection with HBV, HCV, and HIV. Vitiligoid lesion in the balanopreputial region resulting from cryotherapy as a treatment to condyloma two years earlier, with no serology request

Received on 27.11.2015

Approved by the Advisory Board and accepted for publication on 18.02.2016

* Work performed at School of Medical Sciences - Universidade Estadual de Campinas (FCM-UNICAMP) - Campinas (SP), Brazil.

Financial support: none.

Conflict of interest: none.

Division of Dermatology and Division of Medical Education of the School of Medical Sciences - Universidade Estadual de Campinas (FCM-UNICAMP) Campinas (SP), Brazil.

C2017 by Anais Brasileiros de Dermatologia 
serodiscordant couples who used condoms inconsistently and/or improperly were not effectively protected. ${ }^{7}$

Responsibility: responsibility for one's own health and for the partner's health should be encouraged by doctors who instruct patients or the general population. Although partner notification should be made by the patient, doctors are also responsible for making sure that the partner has been really notified. ${ }^{8}$

Other instructions: It is important to inform any individual that having a STI increases 18 times the risk of HIV infection. ${ }^{8}$ According to the World Health Organization, the most effective way to prevent infection by sexually transmitted agents is to abstain from sexual intercourse (oral, vaginal, or anal) or to have sexual intercourse only with longstanding uninfected partners in mutually monogamous relationships. ${ }^{9}$

Laboratory tests of other STIs: any patient who has been exposed to infection by a sexually transmitted agent may have been infected by others. Therefore, serological investigation for HIV, syphilis, and hepatitis B and C is essential. ${ }^{9}$ Repeat tests are necessary due to incubation period of each infection.

Immunization against hepatitis B: any patient who has an STI and that is not protected against hepatitis B should be vaccinated.

Various: at least two patients. Any STI involves inter-human transmission, and evaluation of sexual partner(s) involved in the index case is required. Special care should be given to cases of viral diseases whose infection may have preceded a period of stable and monogamous relationship. However, physicians must take into consideration the impact of this diagnosis when counseling the couple. ${ }^{10}$ Another instruction is that the patient is initially responsible for referring a sex partner for evaluation. In case of refusal, it is an ethical duty of the physician to do so, as suggested by the STD Manual of the Brazilian Ministry of Health. ${ }^{8}$

Ensure: Case history and physical examination should be emphasized: often times, the history of another STI can be used to assess risks and to guide specific treatment or orientations. Patients usually omit, voluntarily or involuntarily, their medical history initially. In addition, general physical examination, especially inspection of the genital, perianal, and oral mucosa regions, must always be performed even in case of a risk of exposure.

Single treatment dose- whenever possible: Several treatment regimens are available to treat different curable sexually transmitted diseases (STDs). As a rule, medical and health care should prioritize single-dose regimens in order to reduce the possibility of poor adhesion, so common in the treatment of these diseases.

The mnemonic method presented herein is intended to facilitate basic behaviors before any patient diagnosed with STIs or even patients that only report risk of exposure to infection by these agents. $\square$

\section{REFERENCES}

1. Who.int [Internet]. World Health Organization. Sexually transmitted infections (STIs). [Cited 2014 Nov 28]. Available from: http://www.who.int/mediacentre/ factsheets/fs110/en/2013

2. Forman P. (Re)cognizing postmodernity: helps for historians--of science especially. Ber Wiss. 2010;33:157-75

3. Wu JJ, Huang DB, Pang KR, Tyring SK. Selected sexually transmitted diseases and their relationship to HIV. Clin Dermatol. 2004;22:499-508

4. Galvin SR, Cohen MS. The role of sexually transmitted diseases in HIV transmission Nat Rev Microbiol. 2004;2:33-42.

5. Lima LHM, Gurgel MFC, Moreira-Silva SF. Avaliação da sífilis congênita no Estado do Espírito Santo. DST J Bras Doenças Sex Transm. 2006;18:113-6.

6. Santos Júnior A, Andrade MGG, Magalhães RF, Moraes AM, Velho PENF. Sorologia para sífilis: os médicos estão capacitados a interpretá-la? An Bras Dermatol. 2007;82:183-5.

7. Smith DK, Herbst JH, Zhang X, Rose CE. Condom effectiveness for HIV prevention by consistency of use among men who have sex with men in the United States. J Acquir Immune Defic Syndr. 2015;68:337-44.

8. Brasil. Ministério da Saúde. Secretaria de Atenção à Saúde. Departamento de Atenção Básica. HIV/Aids, hepatites e outras DST. Brasília: Ministério da Saúde, 2006. 197 p. il. - (Cadernos de Atenção Básica, n. 18) (Série A. Normas e Manuais Técnicos).
9. Workowski KA, Berman S; Centers for Disease Control and Prevention (CDC). Sexually transmitted diseases treatment guidelines, 2010. MMWR Recomm Rep. 2010;59:1-110.

10. Sousa L, Barroso M. DST no âmbito da relação estável: análise cultural com base na perspectiva da mulher. Esc Anna Nery Rev Enferm. 2009;13:123-30.

\author{
MAILING ADDRESS: \\ Paulo Eduardo Neves Ferreira Velho \\ Rua Tessália Vieira de Camargo, 126 \\ Cidade Universitária "Zeferino Vaz" \\ 13083-887 - Campinas - SP \\ Brazil \\ E-mail:pvelho@unicamp.br
}

How to cite this article: Velho, PENF. Sexually transmitted infections and PRO-LIVES: based on a clinical report. An Bras Dermatol. 2017;92(1):279-80. 